\title{
Incorporating Different Designs of Interaction into Vocabulary Instruction: Its Effect on Learners' Lexical Depth in an EFL Context
}

\author{
Masoud Zoghi \\ Department of ELT, Ahar Branch, Islamic Azad University, Ahar, Iran \\ E-mail: m-zoghi@iau-ahar.ac.ir \\ Alireza Moradinejad (Corresponding author) \\ Islamic Azad University of Telesh, Guilan, Iran \\ E-mail: alireza_moradinejad@yahoo.com
}

Doi:10.7575/aiac.alls.v.7n.4p.7

URL: http://dx.doi.org/10.7575/aiac.alls.v.7n.4p.7
Received: 10/02/2016

Accepted: 18/04/2016

\begin{abstract}
This study examined the effect of the interaction approach on young EFL learners' lexical depth in a private language institute in Talesh, Iran. To achieve this, a Michigan test was administered to 40 EFL learners. Those language learners who met the selection criterion, i.e., performed one standard deviation above and below the mean on the test were divided into two classes $(\mathrm{N}=28)$ : group $\mathrm{A}(\mathrm{N}=14)$ and group $\mathrm{B}(\mathrm{N}=14)$. In both groups, the interaction approach was incorporated into vocabulary instruction. However, the design of the interaction was different in each group. In group A, interactions were mostly between learners. On the other hand, in group B, learners mainly interacted with the teacher. After 18 weeks of instruction, a test of lexical depth, word association tasks (WAT), was administered to the both groups. The results of statistical analysis showed that the standard deviation (SD) was almost the same in both groups. However, the mean in group B significantly outperformed group A. A $t$ test was used to compare means of test scores between groups. The findings of this study suggest that learner-teacher interaction is a more effective design in the improvement of learners' knowledge of vocabulary depth in comparison with learner-learner interaction.
\end{abstract}

Keywords: Comprehension, Interaction, Negotiation for meaning, Knowledge of vocabulary depth, Word association task

\section{Introduction}

It has been observed by many researchers that vocabulary knowledge involves more than remembering the meaning of a specific word (Nation, 1994; mentioned in Jafarpour, 2014). In fact, the knowledge of vocabulary has two major dimensions: breadth and depth. Vocabulary breadth relates to the number of vocabulary items whose meanings are known to learners superficially. However, depth of vocabulary refers to how well a learner knows a word (Marzban \& Hadipour, 2012; Shen, 2008). The latter is also defined as "one's level of understanding of various important aspects of a word" (Qian, 1998, p.13). This dimension of vocabulary is important "because it dictates the manner in which lexical items can be utilized" (Schmitt et al., 2011, p.106).

Knowledge of vocabulary depth has been of great interest to many researchers and much research has focused its effort on the relationship between knowledge of vocabulary depth and some other parts of language. For example, Shen (2008) and Sen and Kuleli (2015) investigated the roles of depth of vocabulary knowledge in reading. Nassaji (2004) and Hatami and Tavakoli (2012) examined the relationship between depth of vocabulary knowledge and L2 learners' lexical inferencing and success. However, only recently, researchers have shown an interest in putting various means to use in order to increase learners' knowledge of vocabulary depth. Jafarpour (2014), for example, used the extensive reading approach to improve learners' knowledge of lexical depth. On the other hand, very few studies have been done regarding the effect of interaction on vocabulary knowledge. In a rare study, for example, Hashemi Shahraki and Kassaian (2011) investigated the effects of three different tasks on the acquisition of new EFL vocabulary items. They formed three learning groups: receptive, productive, and negotiated interaction (NI). Two aspects of vocabulary knowledge, that is, receptive and productive were assessed using L1 translation and sentence construction tests, respectively. The results showed that the NI significantly outperformed the other two groups in acquiring receptive and productive vocabulary. Their study indicated that the students' interaction and productive use of vocabulary items were likely to lead to the better acquiring of receptive and productive vocabulary. Surprisingly, no research has been carried out about vocabulary instruction through the interaction approach and its effect on knowledge of lexical depth particularly with the focus on the difference between learner-learner and learner-teacher interaction. Therefore, this paper attempts to fill the gap and supplement the existing studies of vocabulary instruction. It is also sought to broaden the scope of lexical depth literature by reporting on a use of different designs of interaction in EFL vocabulary 
instruction. Specifically, it will be shown how vocabulary instruction through incorporation of various interactional designs in EFL classes will increase readers' knowledge of lexical depth.

\subsection{The Interaction Hypothesis}

Over the last decades, the role of comprehension in second language acquisition (SLA) has been investigated by many studies. Krashen (1985) introduced an overall theory of SLA, which comprised five hypotheses: (1) the acquisitionlearning hypothesis (2) the natural order hypothesis (3) the monitor hypothesis (4) the input hypothesis (5) the affective filter hypothesis. To him the input hypothesis was of primary importance. According to his input hypothesis, the only way to acquire language is understanding the message, that is, receiving comprehensible input. Confirming and building on the input hypothesis, Long (1983a) proposed the interaction hypothesis. He argued that "linguistic input probably has to be comprehensible to the learner if it is to serve as data for second language acquisition" (Long, 1983a, p.126). In the same year, Long (1983b) summarized the all evidence of input hypothesis: (1) access to comprehensible input is a characteristic of all cases of successful first and second acquisition, (2) greater quantities of comprehensible input seem to result in better or faster acquisition, (3) lack of access to comprehensible input leads to little or no acquisition. In the same study, however, he argues that "like any genuine hypothesis, the input hypothesis has not been proven. There has been no direct test of it to date" (p.98).

Unlike the input hypothesis, the interaction hypothesis contends that "comprehensible input alone is insufficient", though necessary (Long, 1996, p.424). In effect, input should become comprehensible "through the speech modifications of native speakers addressing non-native speakers of the target language" (Long, 1983a, p.126). Long (1996) gives three reasons in order to support the idea of insufficiency of comprehensible input: First, of some learners who have lived in an L2 environment for several years, many cases have communication problems; this suggests that communicative motivation alone is not enough for L2 development. Secondly, many advance learners cannot have a complete lexical and grammatical knowledge even as native children. Thirdly, researchers have argued that negative evidence is necessary in order to get a native-like proficiency.

Overall, Long was concerned with the way and the condition under which the input becomes comprehensible. For input to become comprehensible, Long (1983a) suggested fifteen devices under three categories: (1) strategies to avoid conversational troubles, (2) tactics to repair the discourse when facing conversational troubles, (3) strategies and tactics to achieve both purposes. Long (1983b) suggests three other ways: one way is through the modifications that competent speakers make when they talk to learners. However, this kind of modification of the input can "serve only the immediate needs of communication, not the future interlanguage development of the learner, for by definition it denies him or her access to new linguistic material" (p.101). The second way is the use of linguistic and extra-linguistic context, and here and now orientation in adult-adult conversation. The third way is modifying the interactional structure of conversation. This last one is the most important and most widely used way.

Long (1983b) also suggests that the use of tasks with a two-way information exchange, in a small group, is one way of introducing more communicative language use in the second language (SL) classroom, and as a result, more comprehensible input. The need to provide and receive unfamiliar information in two-way tasks will lead to the negotiation for meaning which is featured by modifications in the interactional structure of conversation in an attempt by participants to make the input comprehensible. Long (1996) writes negotiation for meaning is

the process in which, in an effort to communicate, learners and competent speakers provide and interpret signals of their own and their interlocutor's perceived comprehension, thus provoking adjustments to linguistic form, conversational structure, message content, or all three, until an acceptable level of understanding is achieved. (p.420)

Ellis and Barkhuizen (2005) use the term negotiation of meaning instead and define it as "the conversational exchanges that arise when interlocutors seek to prevent a communicative impasse occurring or to remedy an actual impasse that has arisen" (p.167). It is argued that interaction modification results in L2 development and more active involvement in negotiated interaction results in greater development of language (Mackey, 1999). In other words, learners by facing incomprehension find out that their present interlanguage is insufficient and therefore restructure it. Interactional adjustments help the comprehension and invite the learner's attention to specific information. This interaction leads to more effective communication and further stage in acquisition on the part of the learner (Soler, 1996).

According to Mackey (1999), the nature of the interaction, the role of the learner, and the type of structure are three important factors that are affected through interaction. She suggests that learner participation in interaction, which offers opportunities for the negotiation for meaning, is one of the features that interacts with the learner-internal factors to facilitate language development. This interaction is effectively achieved through the use of tasks.

In a similar vein, Loschky (1994)'s study showed that "all other things being equal, learners who are allowed to negotiate interaction while listening to the target language have a higher probability of comprehending what they hear" (p.318). He also added that more incomprehension on the learner's part makes negotiated interaction more important.

In fact, there are two claims regarding the interaction hypothesis: (1) languages acquisition requires comprehensible input (e.g. Long, 1996; Pica, 1987), (2) linguistic and conversational modifications which take place in the process of negotiation for meaning improve the comprehensibility of input (e.g. Long, 1996; Loschky, 1994; Pica, 1987). In terms 
of the first claim, Ellis (1991) contends that the fact that comprehending messages in an L2 aids the language acquisition has not been proved let alone that it is necessary for its acquisition. On the other hand, he argues that the lack of direct evidence does not prove the rejection of input hypothesis. In fact, if there are sufficient indirect evidence the input hypothesis can be sustained. In terms of the second claim, he argues that "the research to date only suggests that simplified input helps comprehension" and regarding whether and when input should be modified interactionally, more work are required. However, this aspect of hypothesis looks promising (p.18). He rightly goes on arguing that there are two options: one option is to abandon the hypothesis (the one that is not to his liking). The second option is the revision of the hypothesis. He favors the second option since, to him, the interaction hypothesis has made a valuable contribution to L2 research and has strong face validity. The revisions that he made to the interaction hypothesis are as follows:

1) It is necessary to make a weaker claim regarding comprehensible input. It must be considered facilitative rather than necessary in acquisition.

2) Modified input enables learners to carry out the preliminary processes of acquisition, that is, noticing and comparison.

3) Output plays a role in the hypothesis. Output is seen as a mechanism that facilitates the integration of new linguistic knowledge.

Moreover, in the same article and after reporting some of Long's early works on the interaction hypothesis, he suggests an amendment to the description of interaction hypothesis: "tasks in which there is a need for the participants to exchange information with each other promote more interactional restructuring" (p.7). That is, information exchange tasks help L2 comprehension and acquisition. He also reports on Pica (1987)'s work and suggests another amendment to the description of the interaction hypothesis: "a situation in which the conversational partners share a symmetrical role relationship affords more opportunities for interactional restructuring" (p.8). That is, the equality of status between the leaner and their interlocutor facilitates comprehension and acquisition.

The shift in Long' claim regarding the interaction hypothesis seems a gradual change from his early work to his later work in response to the shortcomings of the early version of the interaction hypothesis. To Ellis (1991) the main difference between their early and later work is that in the latter the interaction hypothesis is no longer seen as the only, though an important element, way of L2 acquisition.

Finally, in 1996, Long himself after arguing that both environment and innate knowledge are needed in order to have a working hypothesis for L2 acquisition, proposed his updated version of the interaction hypothesis. The updated version gives a way better explanation of the role of interaction in language acquisition. He points out that

environmental contributions to acquisition are mediated by selective attention and the learner's developing L2 processing capacity, and that these resources are brought together most usefully, although not exclusively, during negotiation for meaning. Negative feedback obtained during negotiation work or elsewhere may be facilitative of L2 development. (Long,1996, p.417)

Linguistic environment for SL includes both positive and negative evidence. The updated version of interaction hypothesis put emphasis on cognitive processing- attention, awareness, focus on form, and negative evidence. Attention is necessary to extract specific items from input and to store them in long-term memory. Awareness or understanding is concerned with a higher level of language and implies recognizing a general rule or pattern. He distinguishes noticing from awareness: Noticing means registering the occurrence of some event and any claim regarding the necessity of it for L2 acquisition in the higher level of understanding would be problematic. Focus on form refers to paying attention to language as object, in a meaning-oriented task. That is, "learners need to attend to a task if acquisition is to occur, but that their orientation can best be to both form and meaning, not to either form or meaning alone." (Long, 1996, p.430). Finally, negative evidence refers to "alerting the leaner to the existence of error" (p.431). The main form of providing negative evidence is through recasts which are "utterances that rephrase a child's [or learner's] utterance by changing one or more sentence components (subject, verb, or object) while still referring to its central meanings" (Long, 1996, 435). He also considers a role for modified output in his revised hypothesis. During the negotiation for meaning, learners receive feedback on their deviant productions, through which they can adjust themselves. Theses "tentative adjustments to the IL grammar can be tested very quickly if they are reflected in the learner's modified output and in turn elicit feedback" (p.451). The later version of interaction hypothesis also emphasizes that interactional adjustment triggered by negotiation for meaning "facilitates acquisition because it connects input, internal learner capacities, particularly selective attention, and output in productive ways" (Long, 1996, p.450). Tasks are also of prime importance in the revised version of the interaction hypothesis "for they may be one of the easiest ways to facilitate a learner's focus on form without losing sight of a lesson's (or conversation's) predominant focus on meaning” (p.453).

In 2007, Nick Ellis argued for the influence of social interaction in language acquisition. He pointed out that "we learn to comprehend speech as spoken by speakers, and there is considerable research demonstrating that we learn embodied speech in social interaction more easily than we do the acoustic signals of recorded speech" (p.18). He also claims that usage of a necessary-for-communication construction leads to acquisition. Interaction with a native speaker, which is scaffolding the use and acquisition of an unknown construction by allowing the learner to notice its form, can help the learner shape it.

Schmidt (2010) places emphasis on individual differences and asserts that since many language learners who limit themselves to interaction and exposure cannot achieve native-like competency in grammar, it is possible to come to the 
conclusion that "individual differences in the degree to which learners pay attention to and notice grammatical features of the input may partly account for their relative success in this aspect of language learning" (p.731).

In addition, there has been some research concerning the nature of interaction in classroom settings. In 1987, Pica argued that mutual understanding is achieved when learners and competent speakers restructure their interaction to check clarification, confirmation, and comprehension. To reach such an understanding, learners and their interlocutors should have unequal language proficiency. What she highlighted is that learners and their interlocutors should have "equivalent status with regard to meeting their needs and fulfilling their obligations as conversational participants" (p.4). To her, this is not the case in most classroom interactions where needs between teachers and learners are unequal. He writes

The teacher is perceived as both language expert and evaluator. The students come to the lesson as subordinates, seeking the teacher's expertise to guide and evaluate the progress of their leaning. Decisions as to what knowledge and skills are to be displayed are therefore seldom within the student's control, but rather, are shaped, or, unfortunately, at times constrained by the teacher's elicitations and directives. (p.8)

He concludes that restructuring and modifying the interaction become difficult and unnecessary to reach mutual understanding.

Pica (1987) also gives three reasons for the absence of sufficient interactional modification and restructuring toward mutual comprehension in many language-learning activities:

1) Many activities give opportunities to avoid interaction because they are organized in a way that are suitable for mutual comprehension.

2) Mutual comprehension is often achieved through classroom discourse; there is little need to restructure interaction.

3) Teachers misinterpret efforts to achieve comprehension through restructuring of social interaction as challenges.

Wang (2013) highlighted the role of teachers, teachers' feedback, and gender in the classroom interaction. He argues that learners can become aware of the difference between their interlanguage and the target language if they are provided with proper feedback. Peer feedback has a positive effect on boys only, whereas teacher feedback has a positive influence on both genders.

\subsection{Lexical Depth}

Vocabulary knowledge can be characterized as both the number of lexical items known i.e. vocabulary size and how well these items are mastered i.e. vocabulary depth or quality (Schmitt et al., 2011).

Some studies have tried to characterize different components of vocabulary depth. To Qian (1998), a working definition of vocabulary depth includes the following main aspects:

- Pronunciation and spelling: Knowing how a word is pronounced and spelled

- Morphological properties: Knowing the word's stem, its inflection, derivation, and other word formation devices, and its parts of speech

- Syntactic properties: Knowing the word's positions and its syntagmatic relations, with other words

- Meaning: Identification of the denotative meaning of a word in context, knowledge of connotations, as well as polysemy, antonymy, synonymy and other paradigmatic relations

- Register, or discourse features: Adherence to a stylistic, social or regional variety, and the field, mode and manner of discourse concerning the application of the word

- Frequency of the word in the language: Being a commonly used word or a rarely used one

In a similar vein, Nation (1990) described the word knowledge as consisting of eight word categories: spoken form, written form, grammatical behavior, collocations, frequency, stylistic register, meaning, and associations of a specific word (mentioned in Dóczi, 2006).

Needless to say, exploring depth of vocabulary knowledge is time-consuming and complicated since it is very difficult to investigate all the components of lexical depth (Dóczi, 2006). Moreover, it is not rational to elicit all that learners may know about a particular word unless for specific research purposes (Read, 2007). The type of test that has been selected for the purpose of this study is Read's $(1993,1998)$ word association format. This is the basic technique in order to explore the lexical network (Read, 2004).

\subsection{Word Associations Task (WAT)}

The common format for testing the size or breadth of vocabulary is the ability to associate a word with its meaning. However, in order to assess the ability of functional uses of vocabulary, the vocabulary depth should be tested, which in turn includes the pronunciation of a word and its spelling, the morphological forms of a word, its frequency etc. (Read, 2007). Many researchers have designed different ways to assess the depth of word knowledge. Read (1993, 1998) constructed WAT to measure the learner's lexical depth. The recent version of the WAT was used in the present study and it was found reliable, with a coefficient of 0.93 (Read, 1998).

WAT is based on the idea of word association. Each item comprises one target word and eight other words (four adjective and four nouns within two separate boxes). There are four correct answers for each item. The relationships 
among words are of two kinds: meaning (semantic) and collocation (syntagmatic). The purpose is to assess deep vocabulary knowledge. The WAT consists of 40 items.

A sample test item taken from the instruction part of the test is provided below:

Sudden

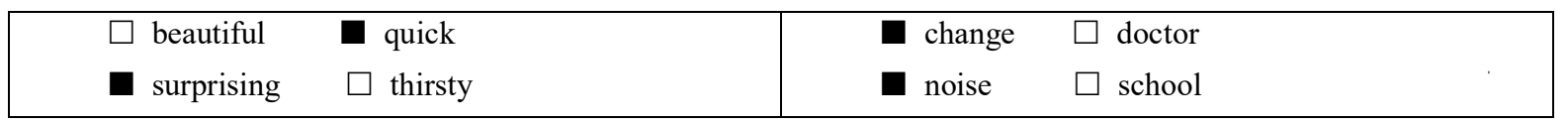

There are many advantages to use WAT: while it has a simple and quick procedure, it gives much richer data about the respondent in comparison with traditional vocabulary tests (Schmitt, 1998). Scoring is also rapid and economical and highly reliable.

Consequently, the present study seeks to fill the gap and supplement the existing studies of lexical depth and interaction literature by reporting on the following research hypothesis:

1- Incorporating different designs of interaction into vocabulary instruction has a significantly different effect on learners' lexical depth in an EFL context.

\section{Method}

\subsection{Participants}

Twenty eight advanced students participated in this study. All participants were studying English at an English language institute in Talesh, Iran, and were native speakers of Persian. The students were divided into two (fourteen-student) classes. One of these two classes was randomly selected as group A and another as group B. Gender was not considered as a moderator variable in this study. English was the medium of instruction in these classes.

Participants' ages were 19 to 23 and they were both male and female students. They had already studied English for 6 to 8 years, with a mean of 7 years. The main reason for choosing these subjects was that they had a greater chance to improve their vocabulary depth through interaction. The classes met twice a week for about 4 months and each session was between 75 to 90 minutes. The same teacher (the researcher) taught both classes.

\subsection{Materials}

At the beginning of the study, a Michigan Test of English Language Proficiency (1997) was administrated to assess the participants' level of language proficiency. The validity of this test was already presupposed. The reliability index, as estimated through Kuder and Richardson formula (KR-21), was reported to be 0.89 .

The coursebook that they studied was The Speaking Test of IELTS (Ramezanee \& Hakimi, 2004) which has three parts similar to the IELTS Speaking Test. The part one of this book, which deals with learners' ability to answer general questions about their background, nationality, occupation etc., was skipped. The second part, which was the main and common part in both classes, includes 40 topics. Each topic begins with a verbal prompt. The verbal prompt or written input is in the form of a general instruction and is content-based. The main idea of topics (such as An Organized Event, Movie etc.) are given in the very first sentence and are followed by some further instructions which are expected to be included and referred to in the task. A little further down, below each topic, there is a section named "Vocabulary You Need" which lists some sentences, each with a vocabulary item highlighted and a definition of that vocabulary item in front of it. The third part, which was practiced differently in each group, requires interactions.

In order to measure the lexical depth, Read's WAT (1998) was adopted.

\subsection{Procedure}

Before the study began, the learners read a consent form that explained the purpose of the study and they agreed to participate.

In both classes, the second part of the coursebook was the starting point. At the beginning of each session, in both groups after choosing a particular topic which was almost always based on the order of topics introduced in the book, the learners' attention was turned to the verbal prompt. They were asked first to read the instructions provided by the coursebook. Then new vocabulary items in "Vocabulary You Need" section were taught using different techniques such as giving English examples to show how the word is used, asking questions using the new word, drawing pictures to show what the word means, translating the word into the students' own language etc. The learners were also allowed to look up new vocabulary items in their dictionaries, where they needed definitions for a better understanding. In the next phase, the learners had only five minutes to prepare themselves and think of what to say about each item of information. They were recommended to make notes and jot down some key points to help themselves relate the main ideas while they were speaking. After a five-minute preparation time, they delivered a speech about the topic. It should also be mentioned that they were not restricted to the mentioned items of information. Each student in turn spoke to the class for about two to three minutes.

After the monolog talk, each group had a different design of interaction. The interaction in group A was between learners, in pairs. However, they were allowed to change and form new pairs or even discuss in groups. In this phase, they were engaged in a discussion of more abstract issues and concepts that were thematically linked to the topic. They asked each other some questions and were encouraged to take part in an extensive discussion with each other. This part usually took between ten to fifteen minutes. During their discussion, the teachers observed them, advised them, helped them, and introduced some interesting and challenging topics to the learners when the learners sought help. However, 
the main job was the learners' responsibility. The teacher was not a participant in the conversation except to help the learners say in English what they wanted to say.

In group B, learners had a one-to-one discussion with the teachers. The teacher talked and discussed with them individually and asked them more in-depth questions of issues broadly related and linked to the topic. Like group A, the topics, to the extent possible, were away from the learners' immediate personal life and were generalized into other related areas. The only difference between these two groups was the teacher's active participation in group B. During this phase, the teacher gave them useful feedback (mainly through recasts and prompts) by presenting commentaries in the class. In this group, since the teacher had to discuss with the learners individually, this part usually took between twenty five to thirty minutes.

To create an environment which is appropriate for the purpose of the study, the chairs in the class for group A were in a circle around a table and whenever one of the learners had a problem regarding conveying their intention, the teacher came behind them and helped them. However, the chairs in the class for group B were arranged in a semicircle around the teacher, so that the teacher was at the center of the attention.

At the end of the study (after 4 months instruction), the WAT test, which consisted of 40 multiple-choice items, was given to the both classes. Subjects were required to answer to the tests in 30 minutes.

\subsection{Date Collection and Data Analyses}

At the beginning of the study, the Michigan Test was administered to 40 participants, determining their proficiency level, in order to choose homogenous students. Thus, those students (28) who performed about one standard deviation above and below the mean on the test were chosen as advance students. In the next step, and after a time period of 4 months, Read's WAT (1998) was administered to the target groups (28 EFL learners).

In the present study, to assess the learners' knowledge of lexical depth, Read's WAT (1998) was chosen. To avoid cheating, two versions of the test were constructed, which the only difference between them was the order in which they appeared. In each example, there were four correct answers. However, there was not a consistent number of correct answers on the left or on the right. The students were just supposed to try to find four related words for each item. They were given a time limit of 30 minutes to answer the questions. Having taken the test, each student was given a mark out of 160: In scoring, each correct word choice was worth one point. There was no penalty for guessing.

In the current study, there was one dependent variable (knowledge of lexical depth) and one independent variable (an 18 -week period of incorporating different designs of interaction into vocabulary instruction). All four assumptions for a $t$ test were met. To compare means of the test between groups, independent $t$ test was used. In this calculation, the null hypothesis of no difference between groups means was chosen. The alpha level was set to .05.

\section{Results}

Table 1. Descriptive statistics of WAT scores (groups A \& B)

\begin{tabular}{|c|c|c|c|c|c|c|c|c|c|c|c|}
\hline & $\mathrm{N}$ & Range & Minimum & Maximum & Sum & Mean & $\begin{array}{l}\text { Std. } \\
\text { Deviation }\end{array}$ & Skewness & & Kurtosis & \\
\hline & Statistic & Statistic & Statistic & Statistic & Statistic & Statistic & Statistic & Statistic & $\begin{array}{l}\text { Std. } \\
\text { Error }\end{array}$ & Statistic & $\begin{array}{l}\text { Std. } \\
\text { Error }\end{array}$ \\
\hline WAT.A & 14 & 29 & 79 & 108 & 1278 & 91.29 & 9.715 & .531 & .597 & -1.013 & 1.154 \\
\hline WAT.B & 14 & 43 & 81 & 124 & 1451 & 103.64 & 10.544 & -.168 & .597 & 1.137 & 1.154 \\
\hline
\end{tabular}

Statistics for WAT score, for both groups, are presented in Table 1. The means on WAT scores for groups A and B are 91.29 and 103.64, respectively. Similar differences in minimum, maximum, and sum scores were also found. The standard deviation (SD) is almost the same (9.715 and 10.544). The two distributions had neither significant skewness nor kurtosis problems.

Table 2. Independent Samples Test between groups A and B

\begin{tabular}{|c|c|c|c|c|c|c|c|c|c|c|}
\hline & & \multicolumn{4}{|c|}{$\begin{array}{l}\text { Levene's } \\
\text { Equality for } \\
\text { of }\end{array}$} & \multicolumn{3}{|c|}{ t-test for Equality of Means } & & \\
\hline & & & & & & \multirow{2}{*}{$\begin{array}{l}\text { Sig. (2- } \\
\text { tailed) }\end{array}$} & \multirow{2}{*}{$\begin{array}{l}\text { Mean } \\
\text { Difference }\end{array}$} & \multirow{2}{*}{$\begin{array}{l}\text { Std. Error } \\
\text { Difference }\end{array}$} & \multicolumn{2}{|c|}{$\begin{array}{l}95 \% \text { Confidence Interval of } \\
\text { the Difference }\end{array}$} \\
\hline & & $\mathrm{F}$ & Sig. & $\mathrm{T}$ & Df & & & & Lower & Upper \\
\hline \multirow[t]{2}{*}{ WAT } & $\begin{array}{l}\text { Equal } \\
\text { variances } \\
\text { assumed }\end{array}$ & .096 & .760 & -3.225 & 26 & .003 & -12.357 & 3.832 & -20.233 & -4.481 \\
\hline & $\begin{array}{l}\text { Equal } \\
\text { variances } \\
\text { not } \\
\text { assumed }\end{array}$ & & & -3.225 & 25.828 & .003 & -12.357 & 3.832 & -20.236 & -4.478 \\
\hline
\end{tabular}


Table 2 shows the result of an independent $t$ test of WAT scores between group A and group B (M $=-12.357$, at a 95\% confidence). It shows that the difference is statistically significant, $t(28)=-3.225$, at $p<.05,2$-tailed. Therefore, the hypothesis of the study is confirmed. That is, the average difference of -12.357 between WAT scores of group A and group B was statistically significant. This suggests that the students in group B outperformed group A in lexical depth knowledge to a statistically significant degree in the 4-month period, during which they engaged in learning vocabulary through the learner-teacher interaction design.

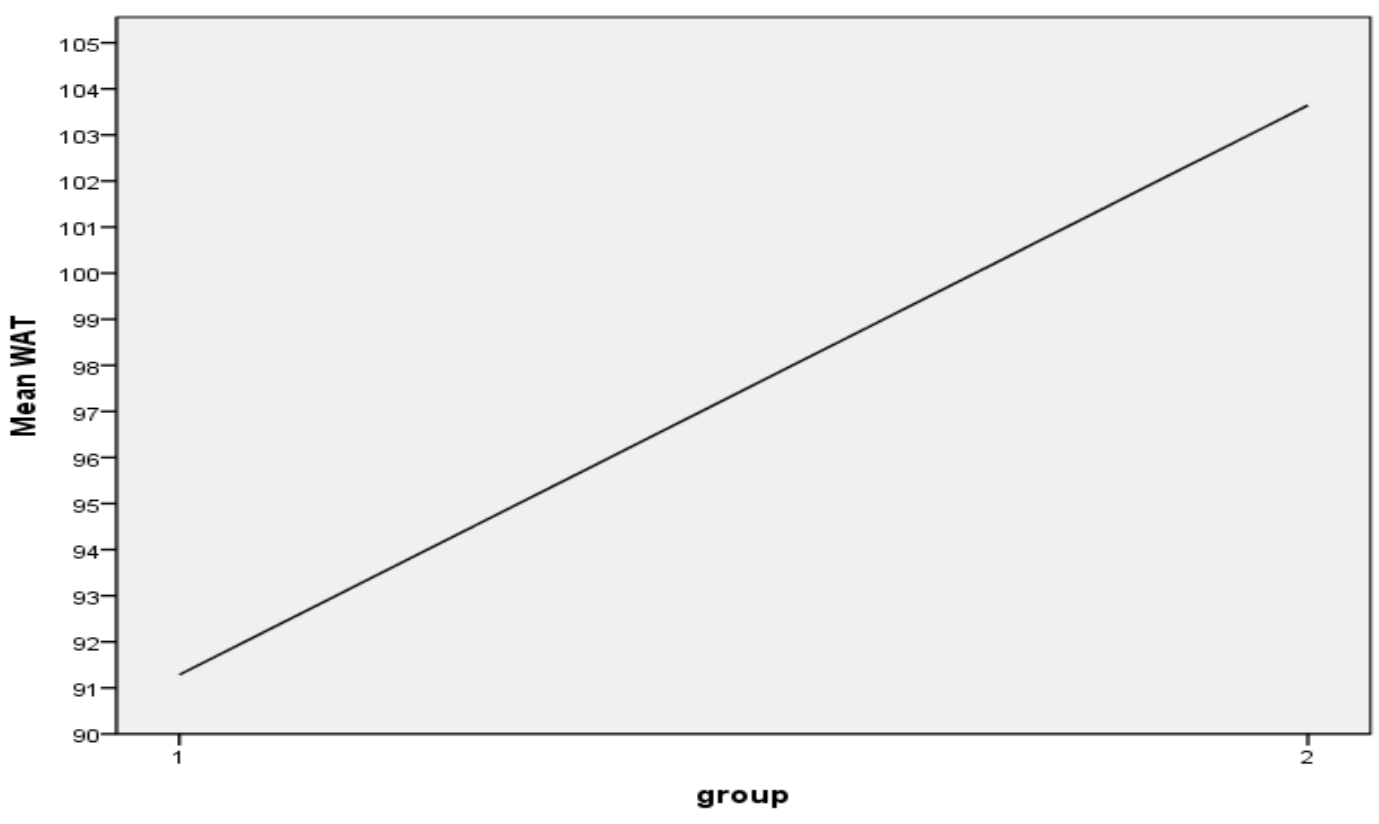

Figure 1. The comparison of each group's mean scores

Figure 1 shows the comparison of groups A and B's mean scores, where no.1 is group A and no.2 is group B.

\section{Discussion and Conclusion}

The results of this study indicated that group B significantly outperformed group A in terms of lexical depth. That is, learner-teacher interaction had a significant improvement over learner-learner interaction. However, to appropriately address the results of the present study, they should be interpreted with caution.

\subsection{Differences in WAT scores}

The difference in the learners' knowledge of lexical depth between the groups is meaningful because the difference is large. Therefore, the results of the present study supported the research hypothesis that the students' lexical depth would improve better through learner-teacher interaction.

Possible explanations for the differences between groups may be found by considering the following two nonpedagogical factors: (a) participants' expectations, and (b) measurement. First, the learners in group B may have expected some improvement in their lexical depth after the treatment. This is because the purposes of the study were explained to them before the study. In addition, the consent form they read revealed the purpose of the study.

Second, the results could be different depending on the way they were measured. In this study, Read's (1998) WAT was selected and the scores of students in answering to the test were considered as a method for measuring knowledge of lexical depth.

\subsection{Implications}

The conclusions reached in this study should be bases on the third phase of the study since the both groups were treated the same in terms of stage two and as it was mentioned above, the first stage was skipped.

The first implication is that the effect of interaction on language development (in this case, lexical depth) is complex. Different designs of interaction have different effects on the improvement of language learners' lexical depth and this difference is meaningful. As a result, generalizations should be made with caution, if any. Unlike Pica (1987)'s argument against the inequality of language proficiency, this study indicated that the learner-teacher interaction, where learners have interlocutors with a higher language proficiency, i.e., the teacher, is a more effective design in comparison with learner-learner interaction. Therefore, learner-teacher interaction should be incorporated into instructional curriculum. Nevertheless, one can argue that this should be done if and only if improving the learners' lexical depth through interaction is of prime importance. That is because it is unclear whether or not the interaction in general or its different designs in specific have a positive significant effect on the improvement of learners' lexical depth in comparison with traditional approaches since there was no control group (using traditional approaches in practicing lexical depth) in this study. 
In group A, since the learners interacted with each other in pairs or groups, they had longer interactions than group B where the teacher had to share the time with all learners. However, group B had a better performance in WAT. Therefore, another implication of the study is that the quantity of the interaction was not an important factor in the improvement of the learners' lexical depth. In other words, it is the quality of interaction that matters.

The higher achievement of learners in group B could have several reasons. First, although the learners in both groups were homogenous in terms of level, in group B, the teacher could play the role of a person who was one layer beyond the learners' current level of language proficiency, which in turn led to improving their lexical depth. However, this was not the case in group A, where most of the interactions were among learners who had the same level of language proficiency. This idea supports Krashen's i+1 theory. Secondly, since the learners in group B interacted with the teacher, the negotiation of meaning was more extensive compared to negotiation of meaning in group A, which in turn led to a greater knowledge of lexical depth. Thirdly, in group B, the teacher consistently provided the learners with feedback (e.g. recasts and prompts) whereas in group A feedback was provided by the learners to each other, if any.

Moreover, as the study took 4 months, it can be concluded that the effect of learner-teacher interaction is significant, in improving lexical depth, in a long-term period. That is "the relationship between interaction and learner intake appears to be a long-term process" (Soler, 1996, p.15). However, it does not reject the effect of the interaction in short term periods.

It is suggested that material producers should pay more attention to the alternative ways of practicing vocabulary in the context of interaction. To the practitioners, the present study suggests that how to teach vocabulary so that the lexical depth of the learners are promoted.

\subsection{Limitations and Delimitations}

The study could have one extra group, that is, a control group to examine the effectiveness of the interaction approach and its different designs in comparison with traditional approaches in terms of leaning vocabulary depth. However, because the number of students involved in this study was not enough for this purpose, only two groups were formed. In addition, the students of only one institute participated in the study.

\subsection{Suggestions for Future Study}

This study used lexical depth. Future researchers may work on other parts vocabulary knowledge such as breadth. The test of the study was in receptive mode, further research can investigate lexical depth in a productive mode.

Moreover, further research might be conducted using a pretest-posttest design where learners' vocabulary depth is measured before taking any specific treatment. Research might also be conducted on learners, whit different pairing arrangements, that is, male pairs, female pairs, and mixed pairs in interactions.

\section{References}

Dóczi, B. (2006). Mapping the mental lexicon of pre-intermediate learners: Word associations in a depth of word knowledge elicitation task. In M. Nikolov \& J. Horváth (Eds.), UPRT 2006: Empirical studies in English applied linguistics, 117-137.

Ellis, N. (2009). The psycholinguistics of the interaction approach. In A. Mackey \& C. Polio (Eds.), Multiple perspectives on interaction: Second language research in honor of Susan M. Gass (11-40). New York: Routledge.

Ellis, R. (1991). The interaction hypothesis: A critical evaluation. In E. Sadtono (Ed.), Language acquisition in the second/foreign language classroom (Anthology Series 28, pp. 179-211). Singapore: SEMEO, Regional Language Centre.

Ellis, R., \& Barkhuizen, G. (2005).Analyzing learner language. Oxford: Oxford University Press.

Jafarpour, M. (2014). The effect of incorporating the extensive reading approach into vocabulary instruction on learners' lexical depth in an EFL context. Advances in Language and Literary Studies, 5 (3), 162- 169.

Hashemi Shahraki, S., \& Kassaian, Z. (2011). Effects of learner interaction, receptive and productive learning tasks on vocabulary acquisition: An Iranian case. Procedia - Social and Behavioral Sciences, 15, 2165-2171.

Hatami, S. \& Tavakoli, M. (2012). The role of depth versus breadth of vocabulary knowledge in success and ease in 12 lexical inferencing. TESL Canada Journal, 30 (1), 1-21.

Krashen, S. D. (1985). The Input Hypothesis: Issues and implications. London: Longman

Long, M. H. (1983a). Native speaker/non-native speaker conversation and the negotiation of comprehensible input. Applied Linguistics, 4, 126-141.

Long, M. H. (1983b). Native/non-native speaker conversation in the second language classroom. In M. Clarke and Handscombe (Eds), Pacific perspectives on language learning and teaching. Washington, DC: TESOL.

Long, M. H. (1996). The role of the linguistic environment in second language acquisition. In W. C. Ritchie \& T. K. Bhatia (Eds.), Handbook of second language acquisition (pp. 413-468). New York: Academic Press.

Loschky, L. C. (1994). Comprehensible input and second language acquisition: What is the relationship? Studies in Second Language Acquisition, 16, 303-325. 
Mackey, A. (1999). Input, interaction and second language development: An empirical study of question formation in ESL. Studies in Second Language Acquisition, 21, 557-587.

Marzban, A. \& Hadipour, R. (2012). Depth versus breadth of vocabulary knowledge: assessing their roles in Iranian intermediate EFL students' lexical inferencing success through reading. Procedia - Social and Behavioral Sciences 46 , $5296-5300$.

Nassaji (2004). The relationship between depth of vocabulary knowledge and L2 learners' lexical inferencing strategy use and success. The Canadian Modern Language Review, 61 (1), 107-134.

Pica, T. (1987). Second language acquisition, social interaction and the classroom. Applied Linguistics, 8, 1-25.

Qian, D. D. (1998). Depth of vocabulary knowledge: assessing its role in adult's reading comprehension in English as a second language. Unpublished doctoral dissertation, University of Toronto, Ontario, Canada.

Ramezanee. A. \& Hakimi. Kh. (2004). The Speaking Test of IELTS. Tehran: Rahnama Press.

Read, J. (1993). The development of a new measure of L2 vocabulary knowledge. Language Testing, 10, 355-371.

Read, J. (1998). Validating a test to measure depth of vocabulary knowledge. Validation in Language Assessment, 4160 .

Read, J. (2004). Plumbing the depths: How should the construct of vocabulary knowledge be defined? In P. Bogaards, \& B. Laufer (Eds.), Vocabulary in a second language (pp. 209-227). Amsterdam: John Benjamins.

Read, J. (2007). Second language vocabulary assessment: Current practices and new directions. International Journal of English Studies, 7 (2), 105-125.

Schmidt, R. (2010). Attention, awareness, and individual differences in language learning. In W. M. Chan, S. Chi, K. N. Cin, J. Istanto, M. Nagami, J. W. Sew, T. Suthiwan, \& I. Walker, Proceedings of CLaSIC 2010, Singapore, December 2-4 (pp. 721-737). Singapore: National University of Singapore, Centre for Language Studies.

Schmitt, N. (1998). Quantifying word association responses: What is native-like? System, 26, 389-401.

Schmitt, N., Wun Ching Ng, J., \& Garras, J. (2011). The word associates format: Validation evidence. Language Testing, 28 (1), 105-126.

Sen, Y. \& Kuleli, M. (2015). The effect of vocabulary size and vocabulary depth on reading in EFL context. Procedia Social and Behavioral Sciences, 199, 555 - 562.

Shen, Z. (2008). The roles of depth and breadth of vocabulary knowledge in EFL reading performance. Asian Social Science, 4(12), 135-137.

Soler, E. (1996). Interaction, foreign language production and development. Miscelánea: A Journal of English and American Studies, 17, 1-16.

Wang, S. (2013). Effects of different negative feedbacks on language output capacity of Chinese EFL learners. Frontiers in Language Teaching and Research (FLTR), (1), 11-15.

Xiao, Z., \& McEnery, A. (2006). Collocation, semantic prosody and near synonymy: A cross-linguistic perspective. Applied linguistics, 27(1), 103-199. 